\title{
The effect of group composition and age on social behavior and competition in groups of weaned dairy calves
}

\author{
G. Færevik, ${ }^{*}$ M. B. Jensen,$\dagger^{1}$ and K. E. Bøe* \\ *Department of Animal and Aquacultural Sciences, Norwegian University of Life Sciences, PO Box 5003, 1432 Ås, Norway \\ †Department of Animal Health and Bioscience, Faculty of Agricultural Sciences, University of Aarhus, PO Box 50, DK-8830 Tjele, Denmark
}

\section{ABSTRACT}

The objective of the present study was to investigate how group composition affects behavior and weight gain of newly weaned dairy calves and how age within heterogeneous groups affects behavior and competition. Seventy-two calves were introduced into 6 groups of 12 calves, of which 3 groups were homogeneous and 3 groups were heterogeneous (including 6 young and 6 old calves). The $9.8 \mathrm{~m} \times 9.5 \mathrm{~m}$ large experimental pen had 4 separate lying areas as well as a feeding area. Behavior and subgrouping were recorded on d 1, 7, and 14 after grouping, and calves were weighed before and after the experimental period of $14 \mathrm{~d}$. Analysis of the effect of group composition on behavior and weight gain included young calves in heterogeneous groups and calves in homogeneous groups within the same age range at grouping (30 to $42 \mathrm{~d}$ ). Irrespective of group composition, time spent feeding and lying increased, whereas time spent active decreased from d 1 to 7 . In homogeneous groups, calves were more explorative on d 1 after grouping. Finally, calves in homogeneous groups had a higher average daily weight gain than calves in heterogeneous groups. Analysis of the effect of age included young and old calves of heterogeneous groups. Young calves were less explorative than old calves. Young calves were more active than old calves on $\mathrm{d} 1$ but less active on $\mathrm{d}$ 7. Time spent lying and lying alone increased over time. More displacements from the feed manger were performed by old calves than by young calves. An analysis including all calves in both homogeneous and heterogeneous groups showed that when lying, calves were evenly distributed on the 4 lying areas and formed subgroups of on average 3 calves. In conclusion, age heterogeneity leads to increased competition, which may have a negative influence on the young calves' performance.

Key words: calves, group housing, age heterogeneity, social behavior

Received February 8, 2010.

Accepted June 2, 2010.

${ }^{1}$ Corresponding author: MargitBak.Jensen@agrsci.dk

\section{INTRODUCTION}

Housing of preweaned dairy calves in groups as opposed to individually in small pens, gives the calves the opportunity to perform normal social behavior as well as play behavior (Jensen et al., 1998; Babu et al., 2004). Calves are less fearful in novel social situations (Jensen et al., 1997, 1999) and they engage more in nonagonistic social interactions when grouped after weaning (Veissier et al., 1994). However, group-housed calves may be subject to competition and this may reduce access of low-ranking individuals to limited resources.

Recent studies on social behavior and competition in groups of newly weaned calves have been carried out in age-homogeneous groups. In this situation, aggression is rare and calves mainly engage in nonagonistic social interaction with their pen mates (Færevik et al., 2007). Still, low-ranking animals are found to be displaced from limited resources such as feed (concentrate) and attractive resting places (Færevik et al., 2007, 2008). In practice, age differences within groups of calves may be larger than in the aforementioned studies, and other studies illustrate that age heterogeneity may increase competition within groups. For instance, Hindhede et al. (1999) found that lightweight heifers had fewer lying periods and performed more abnormal oral behavior than did heavy heifers in weight-heterogeneous groups. No previous study has addressed how age heterogeneity affects social behavior and competition in groups of newly weaned calves.

Weaning represents a challenge to calves. In addition to a change of diet, they are often (re)grouped and have to adjust to a new social environment. Weaning may cause increased activity and vocalization (Thomas et al., 2001; Jasper et al., 2008) as well as reduced play behavior (Krachun et al., 2010) and is often associated with reduced energy intake (Weary et al., 2008). Reduced access to feed in the postweaning period, due to competition, may increase distress associated with weaning and may represent a welfare problem for lowranking animals. The aim of the present study was to investigate how age heterogeneity influences behavior and competition for feed in groups of weaned dairy calves. It was predicted that the level of competition 
would be higher in heterogeneous than in homogeneous groups.

\section{MATERIALS AND METHODS}

\section{Experimental Design}

The experiment was carried out at the Animal Production Experimental Centre at The Norwegian University of Life Sciences (Ås, Norway) from October until May the following year. Seventy-two Norwegian Red Cattle (NRF) male and female calves from the resident herd were used in the experiment. The calves were allocated to 6 groups, of which 3 groups consisted of 12 calves of a similar age (homogeneous groups) and 3 groups consisted of 6 young and 6 old calves (heterogeneous groups). The calves were grouped and introduced to the experimental pen when the youngest calf in each group was 5 wk old. Homogeneous and heterogeneous groups were formed alternately. The experimental period lasted for $2 \mathrm{wk}$. At entry, young calves in the heterogeneous groups weighed on average $56.3 \pm 7.15 \mathrm{~kg}$ and were on average $35.1 \pm 4.41 \mathrm{~d}$ old (range 30-42 d), whereas old calves in the heterogeneous groups weighed on average $88.2 \pm 7.43 \mathrm{~kg}$ and were on average $82.65 \pm 7.73 \mathrm{~d}$ old (range 70-94 d). Calves in the homogeneous groups weighed on average $63.9 \pm 10.3 \mathrm{~kg}$ and were on average $41.1 \pm 6.53 \mathrm{~d}$ old (range 30-54 d). However, only those calves in the homogeneous groups of the same age as young calves in the heterogeneous groups were included in the analyses. These calves $(12,5$, and 3 calves from each of the 3 groups, respectively) weighed on average $58.0 \pm 5.58 \mathrm{~kg}$ and were on average $36.4 \pm 3.17 \mathrm{~d}$ old (range 30-42 d).

\section{Animal Management and Feeding}

The experimental calves were separated from their dams $48 \mathrm{~h}$ after birth and housed individually in strawbedded individual pens $(1.20 \mathrm{~m} \times 1.70 \mathrm{~m})$ that allowed limited physical contact with neighboring calves through bars. All calves, including old calves in heterogeneous groups, remained in individual pens until the study began. For the first $5 \mathrm{~d}$ after birth, calves were given 6 L of colostrum/d. After the colostrum feeding period, calves were given a daily amount of $6 \mathrm{~L}$ of milk replacer (Kalvegodt, TINE, Ås, Norway) from teat-buckets offered in 2 equal-sized daily feedings. In addition to milk, calves were offered concentrate (standard Norwegian calf starter). Initially, calves were offered $1 \mathrm{~kg} / \mathrm{d}$, but once they consumed this, the daily allowance was increased to $1.5 \mathrm{~kg} / \mathrm{d}$. Finally, high quality hay and water were offered ad libitum from birth. Calves in homogeneous groups and young calves in heterogeneous groups were abruptly weaned just before being grouped when the youngest calf in the group was 5 wk old. Also, old calves in heterogeneous groups were abruptly weaned when the youngest of these calves within groups was 5 wk old, but they remained in the individual pens until the heterogeneous groups were formed weeks later.

After introduction to the experimental pen, calves were given $1.5 \mathrm{~kg}$ of concentrate/calf per day in addition to high quality hay ad libitum. Concentrates and hay were provided at the feed manger, the activity area was cleaned, and new straw was supplied daily to the lying areas at $0900 \mathrm{~h}$ and $1700 \mathrm{~h}$. Finally, calves were weighed just before grouping and at the end of the experimental period $14 \mathrm{~d}$ later.

The experiment was carried out in accordance with the current regulations for experiments on live animals in Norway. Calf health was monitored daily during the entire experimental period by experienced stock personnel and appropriate medical treatment given when necessary. One calf from a homogeneous group died of intestinal volvulus before the experimental period and one old calf from a heterogeneous group was taken out of the experiment because of problems after dehorning at $4 \mathrm{wk}$ of age (thus, the experiment was carried out with 11 calves in these groups and 70 calves in total). During the experiment, 3 calves were administered Zoolac Propaste (ChemVet, dk A/S, Silkeborg, Denmark) for mild diarrhea, and 3 calves were administered antibiotic because of fever and coughing. None of these calves had reduced general condition.

\section{Experimental Pen}

The experimental pen $(9.8 \mathrm{~m} \times 9.5 \mathrm{~m})$ consisted of an activity area with concrete floor and, to study subgrouping, 4 equal-sized $(3.7 \mathrm{~m} \times 3.9 \mathrm{~m})$ straw-bedded lying areas separated by 1.5 -m-high solid partitions. Each of the 4 lying areas was large enough to allow all calves to lie in the same area at the same time $\left(1.2 \mathrm{~m}^{2}\right.$ per calf), and the length of the post-and-rail feed manger allowed all 12 calves to eat simultaneously $(0.80 \mathrm{~m}$ per calf). The experimental building was insulated and had automatic ventilation and heating. Temperature was set at $10^{\circ} \mathrm{C}$.

\section{Behavioral Observations}

The individually marked calves were video recorded for $24 \mathrm{~h}$ on $\mathrm{d} 1,7$, and 14 after grouping. Time spent feeding (standing with head over feed manger), lying, standing inactive (standing still, motionless), in activity (walking), and exploring the pen (sniffing or licking floor or fittings of pen) were scored using instantaneous sampling at 15-min intervals. When a calf was lying, 
the lying area and distance to the nearest lying calf were also recorded. If the distance was $\geq 1 \mathrm{~m}$, the calf was scored as lying alone, and if the distance was $<1$ $\mathrm{m}$, the calf was scored to lying close to another calf. When a calf in a heterogeneous group was lying close to another calf, it was recorded whether the nearest lying calf was of the same age or not. In addition, all incidences of displacements from the feed manger were recorded continuously for each calf from feeding at 0900 $\mathrm{h}$ until $1100 \mathrm{~h}$ and from $1700 \mathrm{~h}$ until $1900 \mathrm{~h}$.

For the behavioral elements feeding, lying, lying alone, active, and exploring the percentage of total observations within calf and day was calculated before further analysis. Time spent lying alone was calculated as percentage of total lying observations within calf and day. Data for the number of displacements from the feed manger included many zero observations and before analysis, data were averaged across homogeneous groups and across young and old calves, respectively, in heterogeneous groups.

For calves in heterogeneous groups, time spent lying close to a calf of the same age and lying close to a calf of a different age were calculated as the percentage of total observations lying within calf and day. The difference between time spent lying close to a calf of the same age and to a calf of a different age was also calculated within calf and day.

\section{Social Approach Test}

After 2 wk in heterogeneous or homogeneous groups, respectively, 6 randomly selected calves from each of the 3 homogeneous groups and the 6 young calves from each of the 3 heterogeneous groups were subjected to a social approach test. The test was conducted following the same principle as described in Jensen et al. (1997). All 36 calves were introduced individually into an elongated test arena $(7.2 \mathrm{~m} \times 2.4 \mathrm{~m})$ with 1.80 -m-high solid wooden walls. White lines painted on the concrete floor divided the arena into 6 equal-sized rectangles $(1.2 \mathrm{~m} \times$ $2.4 \mathrm{~m})$. A start box $(1.0 \mathrm{~m} \times 2.4 \mathrm{~m})$ was connected to the entrance door, and an unfamiliar calf was tethered to a ring in the floor at the opposite end of the entrance door. Six unfamiliar female calves (one for each group), selected from the resident herd and of approximately the same age as the calves to be tested, were habituated to the arena and to being tethered. After habituation, all unfamiliar calves stood calmly during the following test session. To habituate test calves to the test situation, they were taken from their home pen one by one and led to the empty test arena the day preceding the test. They were left alone in the pen for 5 min before being returned to their home pen.
On the day of testing, the unfamiliar calf was placed in the test arena before the test calf was haltered, led from the home pen, and placed in the start box. One minute after the test calf had entered the start box, the door was opened and the calf could enter the arena. Calves that did not leave the start box within 1 min were gently pushed into the test arena. During the 5-min test session, a video camera situated above the test arena monitored the calves' behavior. Time until entering the test arena (latency arena) and time until physical contact with the unfamiliar calf (latency calf) were recorded. In addition, duration of time in social contact, or proximity (muzzle within $10 \mathrm{~cm}$ of unfamiliar calf), exploring arena (sniffing and licking pen floor and walls), inactive (standing, motionless for periods of $5 \mathrm{~s}$, or more), as well as number of pushes (muzzle, side of head or shoulder forcible applied to unfamiliar calf), butts (ridges at top of the head forcible applied to unfamiliar calf), mountings (jumping up on back of unfamiliar calf), bouts of locomotion (run, jump, and kick), lines crossed, and vocalization (direct observations) were recorded continuously. Finally, time spent in areas close to the start box (areas 1 and 2), middle areas (areas 3 and 4), and areas close to the unfamiliar calf (areas 5 and 6), were recorded. The calf was recorded as entering a new area when one foreleg had crossed the line.

\section{Statistical Analysis}

Group Composition. The analyses investigating the effect of group composition on behavior and weight gain included the 6 young calves in each of the heterogeneous groups and those calves in homogeneous groups that were of the same age as young calves in heterogeneous groups.

Behavior recorded during $24 \mathrm{~h}$ (feeding, lying, lying alone, active, and exploring) was analyzed using the mixed model procedure of SAS (SAS Institute, 1990; Littell et al., 1996). The mixed model (model 1) included group composition (homogeneous, heterogeneous), sex (male, female), day $(1,7,14)$, and group composition $\times$ day as fixed effects. Group and day within group were included as random effects to account for dependency between calves within groups, and dependency between repeated day observations within group.

Number of displacements from the feed manger was analyzed using a mixed model (model 2) including group composition (homogeneous, heterogeneous), day $(1,7,14)$, and group composition $\times$ day as fixed effects; day within group was included as random effect.

Average daily weight gain was calculated from initial weight and weight at the end of the experiment. The ef- 
fect of group composition on average daily weight gain was investigated using a model (model 3) including group composition (homogeneous, heterogeneous) and sex (male, female) as fixed effects, group as a random effect, and initial weight as a covariate.

Data from the social approach test including latencies (latency arena, latency calf), durations (in social contact or proximity, exploring, inactive), and frequencies (locomotor behavior bouts, pushes, butts, mountings, lines crossed and vocalizations) was analyzed using a model (model 4) including group composition (homogeneous, heterogeneous), and sex (male, female) as fixed effects. Group was included as a random effect. Only the 6 randomly selected calves in each of the 3 homogeneous groups and the 6 young calves in each of the heterogeneous groups were included in this analysis.

Age Within Heterogeneous Groups. The analyses investigating the effect of age among calves housed in heterogeneous groups included the 6 young and the 6 old calves of each of the 3 homogeneous groups. Behavior (feeding, lying, lying alone, active, and exploring, lying close to a calf of the same age, and lying close to a calf of a different age), as well as the difference between lying close to a calf of the same age and a different age, were analyzed using a mixed model (model 5) including age within heterogeneous groups (young, old), sex (male, female), day $(1,7,14)$, and age $\times$ day as fixed effects. Group and day within group were included as random effects.

Data for the number of displacements from the feed manger was analyzed using a mixed model (model 6) including age within heterogeneous groups (young, old), day $(1,7,14)$, and age $\times$ day as fixed effects; day within group was included as a random effect.

\section{RESULTS}

\section{Group Composition}

Analysis of the 24-h observations of behavior showed that the percentage of time spent feeding $\left[13.1^{\mathrm{a}} \pm 1.28\right.$, $19.7^{\mathrm{b}} \pm 1.15,22.7^{\mathrm{b}} \pm 1.15$ (mean \pm SEM; means with different superscripts differ, $P<0.05$ ) for $\mathrm{d} 1,7$ and 14, respectively; $F_{2,7}=33.57 ; P<0.001$ ] and lying $\left(55.8^{\mathrm{a}} \pm 1.51,65.4^{\mathrm{b}} \pm 1.30,62.9^{\mathrm{b}} \pm 1.30 ;\right.$ for $\mathrm{d} 1,7$, and 14 , respectively; $\left.F_{2,7}=14.51 ; P=0.003\right)$ increased from $\mathrm{d} 1$ to 7 . The percentage of time lying alone was not affected by treatment or day (grand mean: $33.3 \pm$ 3.38). The percentage of time active decreased from d 1 to $7\left(5.96^{\mathrm{a}} \pm 0.53,2.11^{\mathrm{b}} \pm 0.44,1.52^{\mathrm{b}} \pm 0.44\right.$; for d 1, 7, and 14, respectively; $F_{2,7}=25.55 ; P<0.001$ ). Percentage of time exploring the pen was higher on $\mathrm{d} 1$ than on $\mathrm{d} 7$ and 14 in homogeneous groups, and on $\mathrm{d} 1$ in homogeneous groups compared with $\mathrm{d} 1$ in heterogeneous groups $\left(9.90^{\mathrm{a}} \pm 1.11,3.79^{\mathrm{b}} \pm 0.85,4.96^{\mathrm{b}} \pm 0.85\right.$, $3.54^{\mathrm{b}} \pm 0.85,5.31^{\mathrm{b}} \pm 0.85,4.85^{\mathrm{b}} \pm 0.85$ for $\mathrm{d} 1,7$, and 14 in homogeneous and $\mathrm{d} 1,7$, and 14 in heterogeneous groups, respectively; $F_{2,7}=14.12 ; P=0.004$ ).

Number of displacements from the feed manger increased over time $\left(0.38^{\mathrm{a}}, 1.73^{\mathrm{b}}, 3.05^{\mathrm{c}}( \pm 0.38)\right.$ for $\mathrm{d} 1,7$ and 14 , respectively; $\left.F_{2,8}=12.18 ; P=0.004\right)$, but there was no effect of treatment.

During the social approach test, calves from homogeneous groups tended to spend more time exploring the test arena than young calves from the heterogeneous groups $\left(35.2 \pm 3.6\right.$ vs. $21.7 \pm 3.0 \mathrm{~s} ; F_{1,4}=7.71, P=$ $0.05)$. Calves in the homogeneous groups had a higher average daily weight gain than calves in heterogeneous groups (744 vs. $577 \pm 38 \mathrm{~g} ; F_{1,4}=9.34 ; P=0.04$ ).

\section{Age Within Heterogeneous Groups}

Within heterogeneous groups, the percentage of time spent lying increased from d 1 to $7\left[57.2^{\mathrm{a}}, 61.8^{\mathrm{b}}, 61.2^{\mathrm{b}}\right.$ $( \pm 1.04)$; for d 1, 7, and 14, respectively; $F_{2,8}=12.36$; $P=0.004]$, whereas lying alone decreased from $\mathrm{d} 7$ to $14\left[33.3^{\mathrm{a}}, 33.3^{\mathrm{a}}, 21.8^{\mathrm{b}}( \pm 4.06)\right.$; for $\mathrm{d} 1,7$ and 14 , respectively; $\left.F_{2,8}=5.26 ; P=0.04\right]$. The percentage of time spent active was higher in young calves than in old calves on d 1, but lower in young calves than in old calves on d $7\left[5.52^{\mathrm{a}}, 1.87^{\mathrm{c}}, 1.24^{\mathrm{c}}, 2.58^{\mathrm{bc}}, 3.48^{\mathrm{b}}, 1.69^{\mathrm{c}}\right.$ $( \pm 0.48)$ for $\mathrm{d} 1,7$ and 14 in young and $\mathrm{d} 1,7$ and 14 in old calves, respectively; $\left.F_{2,8}=12.39 ; P=0.004\right]$.

The percentage of time spent exploring was lower among young calves than among old calves $(4.68 \pm 0.62$ vs. $7.96 \pm 0.62 ; F_{1,4}=13.96 ; P=0.02$ ). Young calves performed fewer displacements from the feed manger than old calves $\left[1.3\right.$ vs. $10.9( \pm 1.7) ; F_{1,2}=31.87, P=$ 0.03].

The difference between lying close to a calf of the same age and lying close to a calf of a different age was significantly different from zero $(t=3.23, P=0.03)$ illustrating a preference for lying close to a calf of the same age rather than to a calf of a different age in both age groups (Figure 1).

\section{Position and Distance When Lying}

When all calves were lying, they were evenly distributed on the 4 different resting areas. The average number of calves in each area was $2.91 \pm 0.03$. There were, however, a few observations with as many as 10 calves lying in the same area at the same time. Within each resting area, the calves formed subgroups (distance between calves $<1 \mathrm{~m}$ ) of $3.15 \pm 0.16$ calves on average. 


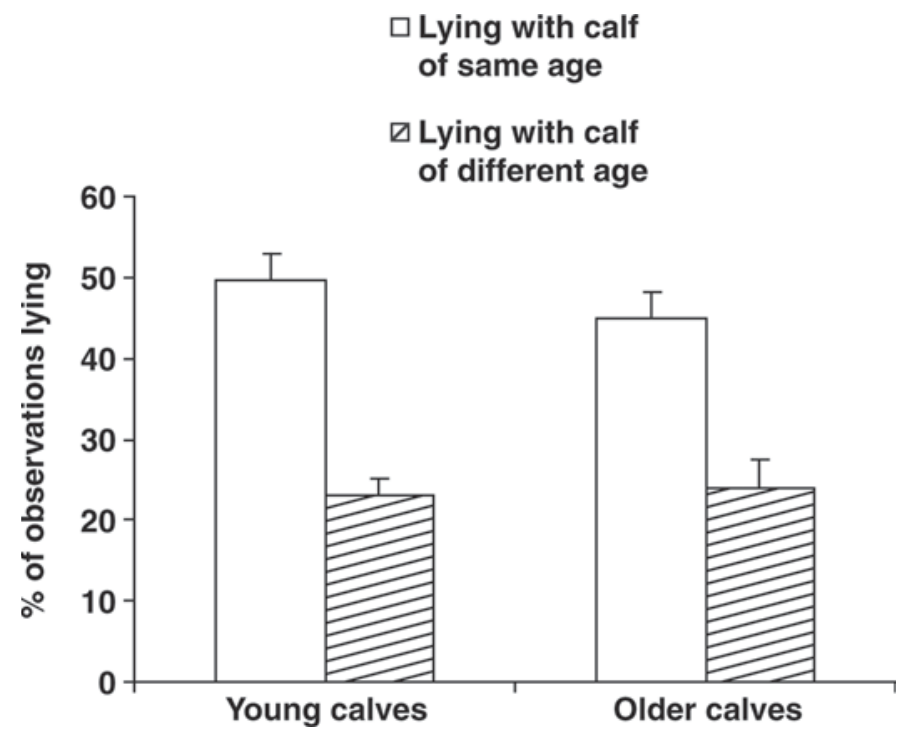

Figure 1. Preference of resting partner (\% of total number of observations lying) within age-heterogeneous groups; least squares means \pm SEM are presented.

\section{DISCUSSION}

\section{Group Composition}

The analysis including young calves in heterogeneous groups and calves in homogeneous groups of the same age showed that time spent feeding and lying was lower, whereas time spent active was higher, on the first day after grouping in all calves. This may be a general response to the novel physical and social environment. Time spent exploring was higher on the first day after grouping in calves of homogeneous groups, but not among young calves in heterogeneous groups. Increased exploration is an expected response to a novel environment and the result may indicate that the presence of old calves in heterogeneous groups suppressed exploration in the young calves. In the social approach test at the end of the experimental period, calves from heterogeneous groups also tended to be less explorative than calves from homogeneous groups. In this test, calves were introduced to an unknown tethered calf of a similar age, and their response suggests that the previous housing with old calves had affected their explorative motivation in a novel situation. Exploration is generally stimulated by novelty and suppressed by fear (Jensen et al., 1997), and the reduced exploration may indicate that calves from heterogeneous groups were more fearful in a novel social situation than calves from homogeneous groups.

Young calves in heterogeneous groups had a lower average daily weight gain than calves of the same age in homogeneous groups, which may illustrate an immedi- ate negative effect of entering a heterogeneous group as a newly weaned calf. Calves were fed concentrates restrictively at the feed manger, and the reduced average daily gain may be explained by young calves having problems competing for concentrates when housed with older calves. Hindhede et al. (1999) found that light heifers gained less weight in large heterogeneous groups than in small homogeneous groups, especially when concentrates were offered restrictively in combination with roughage ad libitum compared with one ration of either silage or TMR. It could be suggested that grouping young newly weaned calves with older calves would stimulate feed intake of young calves. This, however, was not found here, and may require that competition for feed be minimized.

The number of displacements from the feed manger increased in both treatments, which may illustrate that the motivation to access concentrates increased with time after weaning.

\section{Age Within Heterogeneous Groups}

The analysis comparing young and old calves in heterogeneous groups showed that old calves performed more displacements from the feed manger. On the first day after grouping, young calves were more active, perhaps because they were being displaced by old calves and were avoiding old calves. Young calves were generally less explorative than old calves, illustrating that exploration is suppressed in young calves in heterogeneous groups.

\section{Position and Distance When Lying}

Calves at pasture are found to graze and rest close to calves of the same age (Wood-Gush et al.,1984), and these subgroups, or crèches, of calves feeding and resting together are found to consist of 3 or more individuals (Murphy et al., 2000). Correspondingly, results from the present study show that calves in heterogeneous groups prefer a calf of the same age as a resting partner, and the average number of calves resting close together was 3.2 animals. Both familiarity and kinship are suggested to influence calves' social preferences and the formation of subgroups (Kiley-Worthington and de la Plain, 1983; Færevik et al., 2006). In the present study, all calves were housed in individual pens with limited social contact before introduction to the group pen, indicating that proximity in age was essential in the calves' choice of resting partner.

\section{CONCLUSIONS}

Age-heterogeneity leads to increased displacement from the feed manger and reduced weight gain, and 
housing calves in age-heterogeneous groups may influence young calves' behavior and performance negatively. The results emphasize the importance of taking agecomposition into account when newly weaned calves are housed in groups.

\section{ACKNOWLEDGMENT}

This work was recommended by the Nordic Joint Committee for Agricultural Research (NKJ, Jokioinen, Finland) and funded by the Research Council of Norway (Oslo, Norway). The authors thank the staff at the Animal Production Experimental Centre for taking good care of the animals and for good cooperation. We also thank Linda Marijke Dekker Haug (Norwegian University of Life Sciences) for her valuable help with the experiment, and Linn Borsheim (Norwegian University of Life Sciences) for her excellent work with the data collection.

\section{REFERENCES}

Babu, L. K., H. N. Pandey, and A. Sahoo. 2004. Effect of individual versus group rearing on ethological and physiological responses of crossbred calves. Appl. Anim. Behav. Sci. 87:177-191.

Færevik, G., I. L. Andersen, M. B. Jensen, and K. E. Bøe. 2007. Increased group size reduces conflicts and strengthens the preference for familiar group mates after regrouping of weaned dairy calves (Bos taurus). Appl. Anim. Behav. Sci. 108:215-228.

Færevik, G., M. B. Jensen, and K. E. Bøe. 2006. Dairy calves social preferences and the significance of a companion animal during separation from the group. Appl. Anim. Behav. Sci. 99:205-221.

Færevik, G., K. Tjentland, S. Løvik, I. L. Andersen, and K. E. Bøe. 2008. Resting pattern and social behavior of dairy calves housed in pens with different sized lying areas. Appl. Anim. Behav. Sci. 114:54-64.

Hindhede, J., L. Mogensen, and J. T. Sorensen. 1999. Effect of group composition and feeding system on behaviour, production and health of dairy heifers in deep bedding systems. Acta Agric. Scand. A 49:211-220.

Jasper, J., M. Budzynska, and D. M. Weary. 2008. Weaning distress in dairy calves: Acute behavioural responses by limit-fed calves. Appl. Anim. Behav. Sci. 110:136-143.

Jensen, M. B., L. Munksgaard, L. Mogensen, and C. Krohn. 1999 Effects of housing in different social environments on open-field and social responses of female dairy calves. Acta Agric. Scand. A $49: 113-120$.

Jensen, M. B., K. S. Vestergaard, and C. C. Krohn. 1998. Play behaviour in dairy calves kept in pens: the effect of social contact and space allowance. Appl. Anim. Behav. Sci. 56:97-108.

Jensen, M. B., K. S. Vestergaard, C. C. Krohn, and L. Munksgaard. 1997. Effect of single versus group housing and space allowance on responses of calves during open-field tests. Appl. Anim. Behav. Sci. 54:109-121.

Kiley-Worthington, M., and S. de la Plain. 1983. The Behaviour of Beef Suckler Cattle. Tierhaltung, 14. Birkhäuser Verlag, Basel, Switzerland.

Krachun, C., J. Rushen, and A. M. de Pasillé. 2010. Play behaviour in dairy calves is reduced by weaning and by a low energy intake. Appl. Anim. Behav. Sci. 122:71-76.

Littell, R. C., G. A. Milliken, W. W. Stroup, and R. D. Wolfinger. 1996. SAS System for Mixed Models. SAS Institute Inc., Cary, NC.

Murphy, R. M., M. J. R. Paranos, and R. G. Silva. 2000. Creche composition in a group of Angus calves. Page 60 in Proc. 34th Int. Congr. Int. Soc. Appl. Anim. Ethol. A. Ramos, L.C. Pinheiro Machado, and M. J. Hötzel, ed.

SAS Institute. 1990. SAS Users' Guide. Version 6. 4th ed. SAS Institute, Cary, NC.

Thomas, T. J., D. M. Weary, and M. C. Appleby. 2001. Newborn and 5 -week-old calves vocalize in response to milk deprivation. Appl. Anim. Behav. Sci. 74:165-173.

Veissier, I., V. Gesmier, P. Le Neindre, J. Y. Gautier, and G. Bertrand. 1994. The effect of rearing in individual crates on subsequent social behaviour of veal calves. Appl. Anim. Behav. Sci. 41:199-210.

Weary, D. M., J. Jasper, and M. Hötzel. 2008. Understanding weaning distress. Appl. Anim. Behav. Sci. 110:24-41.

Wood-Gush, D. G. M., K. Hunt, K. Carson, and S. G. C. Dennison. 1984. The early behaviour of suckler calves in the field. Biol Behav. 9:295-306. 